\title{
Influence of Carbon Dioxide Fluctuation and Thermal Environment on Workability, Physiology and Psychology
}

\author{
Tomoyuki CHIKAMOTO ${ }^{1, *}$, Ryouto MIMURA ${ }^{2}$ \\ ${ }^{1}$ Department of Architectural and Urban Design, Ritsumenkan University, Kusatsu, Shiga 525-8577, Japan \\ ${ }^{2}$ AXS SATOW INC., Sumida-ku, Tokyo 130-0015, Japan
}

\begin{abstract}
Although carbon dioxide $\left(\mathrm{CO}_{2}\right)$ is a gas not perceived by human, extremely high concentration of $\mathrm{CO}_{2}$ has an influence on the human's health. High concentration of $\mathrm{CO}_{2}$ also leads to lowering concentration ability and promoting drowsiness. It may also have an influence on productivity and learning efficiency of human. We conducted experiments to measure the amount of workability and the physiological and psychological response of the subjects. In the experiment, the concentration of $\mathrm{CO}_{2}$ was set at the constant level at each case. And then, the concentration of $\mathrm{CO}_{2}$ was changed to examine the physiological and psychological response. In the result of the experiment, the $\mathrm{CO}_{2}$ concentration had the influence on productivity and working efficiency of human. Even if the $\mathrm{CO}_{2}$ concentration is not so high, physiological condition of the human would be also affected.
\end{abstract}

\section{Introduction}

Since Pettenkofer proposed that $700-1000 \mathrm{ppm}$ is considered to be an allowable concentration of carbon dioxide $\left(\mathrm{CO}_{2}\right)$ [1], and other researchers started to suggest $1000 \mathrm{ppm}$ of $\mathrm{CO}_{2}$ as a limit value for an adequate ventilated room, many regulations of $\mathrm{CO}_{2}$ density sets around $1000 \mathrm{ppm}$ in office spaces etc.

Although $\mathrm{CO}_{2}$ is a gas not perceived by human, extremely high concentration of $\mathrm{CO}_{2}$ has an influence on the human's health. "Ventilation for Acceptable Indoor Air Quality" (ASHRAE Standard 62.-2016) notes $\mathrm{CO}_{2}$ at very high concentrations (e.g. greater than $5000 \mathrm{ppm}$ ) can pose a health risk. It is also defined that $5000 \mathrm{ppm}$ as the limits of the $\mathrm{CO}_{2}$ density of time-weighted over five 8-hour work day average for industrial environments (TWA) to keep occupational safety and health (The Occupational Safety and Health Administration (OSHA)).

High concentration of $\mathrm{CO}_{2}$ also leads to lowering concentration ability and promoting drowsiness. It may also have an influence on productivity and learning efficiency of human. Satish reported high indoor concentrations of $\mathrm{CO}_{2}(2500 \mathrm{ppm})$ could significantly impair people's decision-making performance [2]. Allen analysed the cognitive function scores with various $\mathrm{CO}_{2}$ density (about $500-1500 \mathrm{ppm}$ ) and other factors, to evaluate the impact of the $\mathrm{CO}_{2}$ level on health and productivity [3].

We have focused on the relationship between $\mathrm{CO}_{2}$ concentration and productivity of human.

We investigated the influence of the $\mathrm{CO}_{2}$ concentration on productivity and learning efficiency of students using the field experiment in the classroom of junior and senior high school [4]. By the results of the surveys, the relationship between the $\mathrm{CO}_{2}$ concentration $(500-1500$ ppm) in the classroom and the productivity was observed statistically. However, the results was obtained by the field experiment, therefore temperature, humidity, illuminance and other factors have changed in the classroom and the influence of $\mathrm{CO}_{2}$ was not caught in the independent event.

This time, we conducted experiments to measure the amount of workability and the physiological and psychological response of the subjects, by using a laboratory room in which not only the $\mathrm{CO}_{2}$ concentration, but also temperature and humidity can be controlled. In the experiment, the concentration of $\mathrm{CO}_{2}$ was set at the constant level at each case to verify the influence of the $\mathrm{CO}_{2}$ concentration. And then, the concentration of $\mathrm{CO}_{2}$ was changed to examine the physiological and psychological response to clarify the mechanism.

\section{Outline of the Experiment}

\subsection{Chamber for the experiment}

The experiments were conducted in a chamber in which both temperature and humidity would be controlled independently. The size of the space is $2060 \mathrm{~mm}$ in width, $2080 \mathrm{~mm}$ in depth and $2700 \mathrm{~mm}$ as the ceiling height. Inside the chamber, supply and exhaust openings were set at the ceiling, and temperature and humidity were kept constant at the target point. The subject sit on the seat. To control the $\mathrm{CO}_{2}$ concentration which would be drawn in subject's breath, the blower unit, which

\footnotetext{
* Corresponding author: tomoyuki@se.ritsumei.ac.jp
} 
would diffuse the air around the subject's nose, was installed as shown in Figures 1-2.

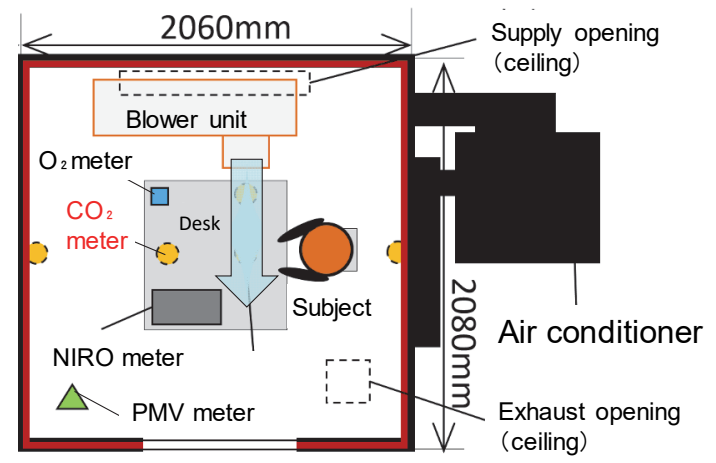

(a) Plan of the chamber.

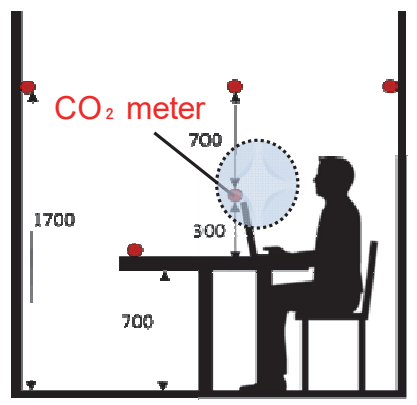

By using the blower unit to diffuse the air around the subject's nose, we assumed that the $\mathrm{CO}_{2}$ concentration of the $\mathrm{CO}_{2}$ meter is the same as the inhaled air of the subject.

(b) Section of the chamber.

Fig. 1. Outline of the chamber.

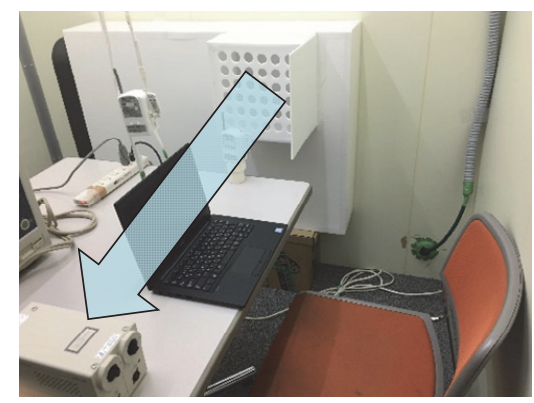

(a) Inside view of the chamber.

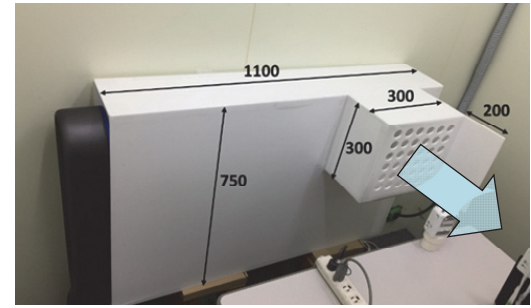

(b) View of the blower unit to diffuse the air.

Fig. 2. View of the chamber.

\subsection{Measurement items}

Temperature, humidity, and the $\mathrm{CO}_{2}$ concentration was measured inside the chamber. The blood pressure, the pulse and the salivary amylase of the subject were measured as a physiological condition. And total oxygen index (TOI), change in concentration of oxygenated haemoglobin $\left(\Delta \mathrm{O}_{2} \mathrm{H}_{\mathrm{b}}\right)$, deoxygenated haemoglobin ( $\Delta$ $\mathrm{HH}_{\mathrm{b}}$ ) and total haemoglobin $\left(\Delta \mathrm{cH}_{\mathrm{b}}\right)$ of the subject's blood flow in the brain were also measured using tissue oxygenation monitor (NIRO meter) that uses near infrared spectroscopy.

\subsection{Outline of the experimental cases}

\subsubsection{Cases analysed}

Table 1. Cases analysed.

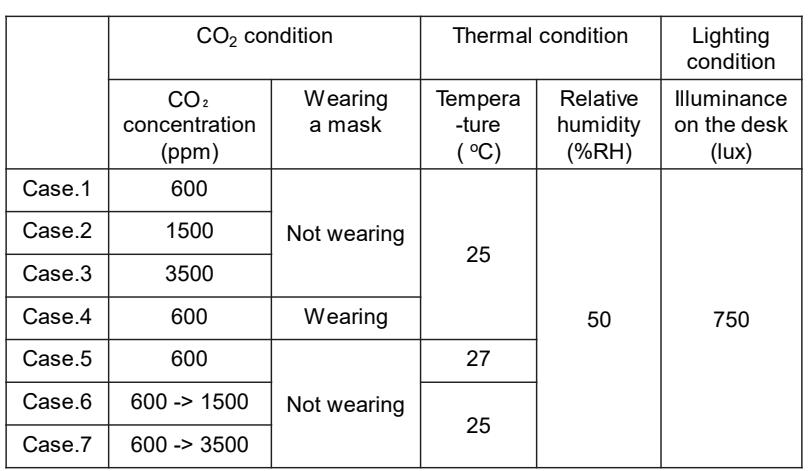

7 cases of experiment were conducted as shown in Table 1.

\subsubsection{Steady $\mathrm{CO}_{2}$ concentration}

In cases from Case. 1 to Case. $5, \mathrm{CO}_{2}$ concentration was set steady in each case. These cases were conducted to verify the fundamental properties of human with different $\mathrm{CO}_{2}$ concentration.

Indoor $\mathrm{CO}_{2}$ concentration was set at $600 \mathrm{ppm}$ (Case.1), $1500 \mathrm{ppm}$ (Case.2) and $3500 \mathrm{ppm}$ (Case.3). The experiment in which the subject had worn the mask was also executed (Case.4). In Case.4, $\mathrm{CO}_{2}$ concentration which would be drawn in subject's breath was assumed $5000 \mathrm{ppm}$, when calculating on the condition that the amount of air between the mask and the face was $150 \mathrm{ml}$, the $\mathrm{CO}_{2}$ concentration of vomited breath was $3.5 \%$, the $\mathrm{CO}_{2}$ concentration of room was $600 \mathrm{ppm}$ and the air leakage rate of mask was $50 \%$.

Indoor air temperature and humidity were kept constant in each case $\left(25^{\circ} \mathrm{C}, 50 \% \mathrm{RH}\right)$. However, effects of the changing room temperature to $27{ }^{\circ} \mathrm{C}$ were also investigated (Case.5).

It is considered that high concentration of $\mathrm{CO}_{2}$ leads to lowering concentration ability and promoting drowsiness. It might also have an influence on productivity and learning efficiency of human. Therefore, the amount of workability, and the physiological and psychological response of the subjects were also measured in these cases.

5 healthy male students were selected for the subjects. The experiment was executed by 25 cases with 5 cases a person in total during October 3 - November 6 in 2017. 
The experiment procedure is shown in Figure 3. First of all, subject stayed for 30 minutes for the adaptation. Then the typing work was done for 60 minutes. Finally, subject rested for 15 minutes. At the measurement A, B and $\mathrm{C}$, the blood pressure, the pulse and the salivary amylase of the subject were measured. TOI, $\Delta \mathrm{O}_{2} \mathrm{H}_{\mathrm{b}}, \Delta$ $\mathrm{HH}_{\mathrm{b}}$ and $\Delta \mathrm{cH}_{\mathrm{b}}$ of the subject's blood flow were measured from $\mathrm{A}$ to $\mathrm{C}$. At $\mathrm{B}$ and $\mathrm{C}$, questionnaire survey had done.

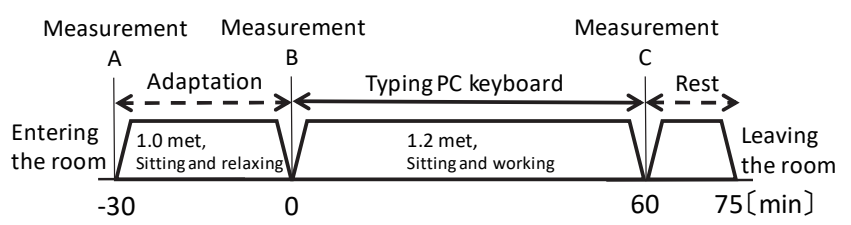

Fig. 3. Time table of the steady $\mathrm{CO}_{2}$ concentration cases.

\subsubsection{Non-steady $\mathrm{CO}_{2}$ concentration}

In cases of Case. 6 and Case. $7, \mathrm{CO}_{2}$ concentration was set non-steady condition in each case. These cases were conducted to assume the actual work environment. In Case.6, the situation when a person entered the office space without enough ventilation was assumed. In Case.7, the situation when several persons entered the meeting room without enough ventilation was assumed. Indoor $\mathrm{CO}_{2}$ concentration was changed from $600 \mathrm{ppm}$ to 1500 ppm (Case.6), from 600 ppm to 3500 ppm (Case.7) in 30 minutes.

3 healthy male students were selected for the subjects. The experiment was executed by 6 cases with 2 cases a person in total during November 10 - 20 in 2017.

The experiment procedure is shown in Figure 4. First of all, subject stayed for 30 minutes for the adaptation. Then the typing work was done for 30 minutes, and during it, $\mathrm{CO}_{2}$ concentration was changed. Finally, subject rested for 30 minutes. Measurement items were the same as steady $\mathrm{CO}_{2}$ concentration cases.

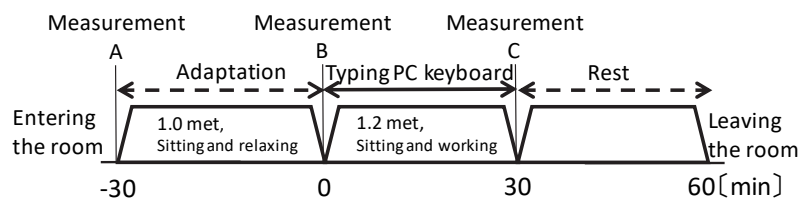

Fig. 4. Time table of the non-steady $\mathrm{CO}_{2}$ concentration cases.

\subsection{4 $\mathrm{CO}_{2}$ concentration of each case}

Figure 5 shows the $\mathrm{CO}_{2}$ concentration of each time in each case. $\mathrm{CO}_{2}$ concentration of Case.1, Case. 2 and Case. 3 was controlled constantly during the experiment. And $\mathrm{CO}_{2}$ concentration was changed from $600 \mathrm{ppm}$ to 1500 ppm (Case.6), from 600 ppm to 3500 ppm (Case.7) gradually from " $\mathrm{B}$ " to " $\mathrm{C}$ " in 30 minutes. Then, $\mathrm{CO}_{2}$ concentration of Case. 6 and Case. 7 was returned to 600 ppm after " $\mathrm{B}$ " in 30 minutes.

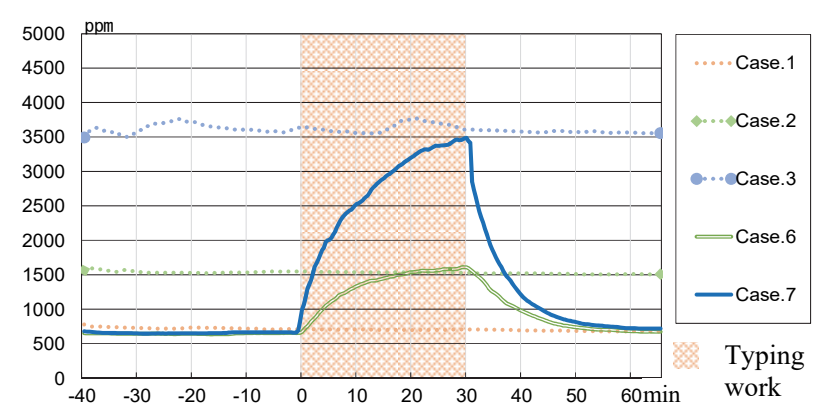

Fig. 5. $\mathrm{CO}_{2}$ concentration in each case.

\section{Results of steady $\mathrm{CO}_{2}$ concentration}

\subsection{Subject declaration}

Because $\mathrm{CO}_{2}$ was a gas not perceived, a significant difference of subject declaration of satisfaction to air quality was not seen between cases in Figure 6 ("B" and "C" in the figures mean the survey done at the measurement $\mathrm{B}$ and $\mathrm{C}$ shown in the timetable Figure 3).

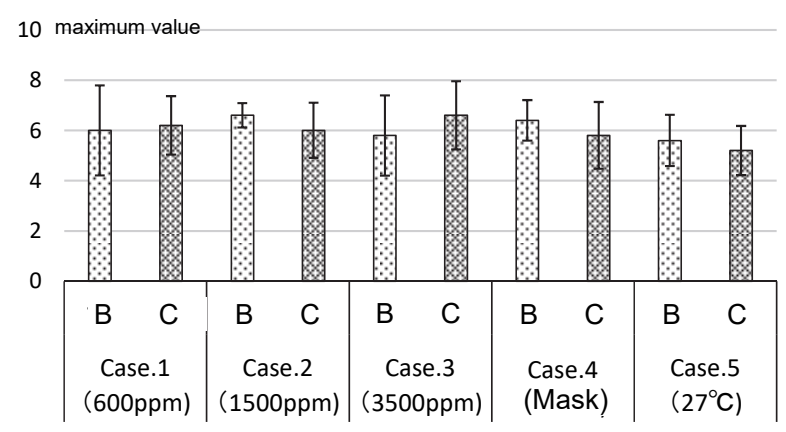

Fig. 6. Subject declaration of satisfaction to air quality.

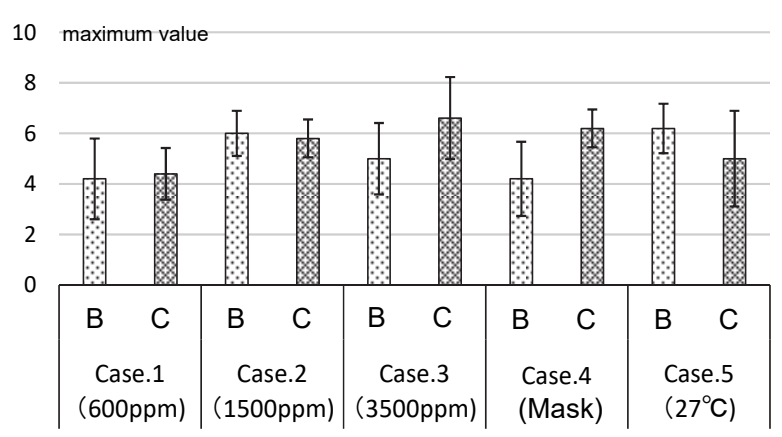

Fig. 7. Subject declaration of drowsiness degree.

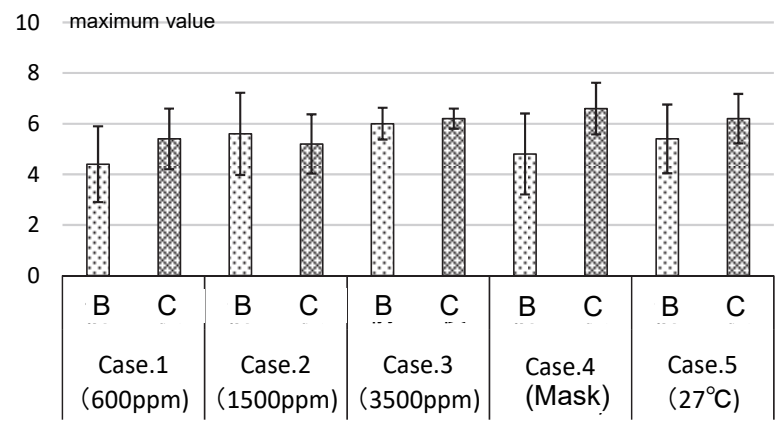

Fig. 8. Subject declaration of worthlessness feeling. 
However, as the $\mathrm{CO}_{2}$ concentration rose, the decreasing tendency was seen in concentration ability and work efficiency, on the other hand increasing tendency was seen in the drowsiness degree and the worthlessness feeling in Figures 7 and 8.

The subject declaration change rates from " $\mathrm{B}$ " to " $\mathrm{C}$ " from Case. 1 to Case. 5 of 4 items (air quality, drowsiness degree, worthlessness feeling and concentrated level) is shown in Figure 9. The difference is seen in Case. 3 and Case.4, and the drowsiness feeling is increased with Case. 4 by $48 \%$, and it has increased with Case. 3 by $32 \%$. The difference of the worthlessness feeling is seen in Case. 4 and the worthlessness feeling of Case. 4 has increased by $38 \%$. As for the concentrated level, Case. 4 has decreased most greatly by $24 \%$.

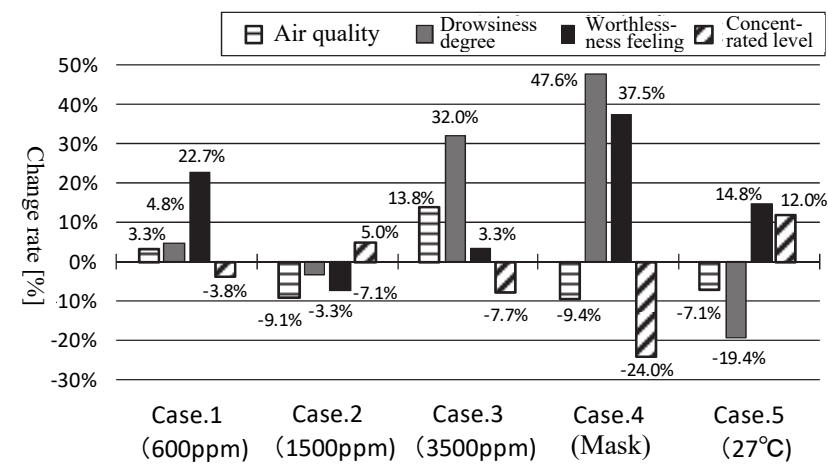

Fig. 9. Subject declaration change.

\subsection{Subject productivity}

Relations between the number of total input characters, correct input characters, ratio of error input characters of the typing test, and the $\mathrm{CO}_{2}$ concentration are shown in Figures $10-13$. The number of total input characters and the number of correct input characters had the decreasing tendency as the $\mathrm{CO}_{2}$ density rose (Figures 10 and 11). The error input rate had the increasing tendency as the $\mathrm{CO}_{2}$ density rose (Figures 12 and 13). However, the temperature change had the little influence on the error input rate (Figure 13).

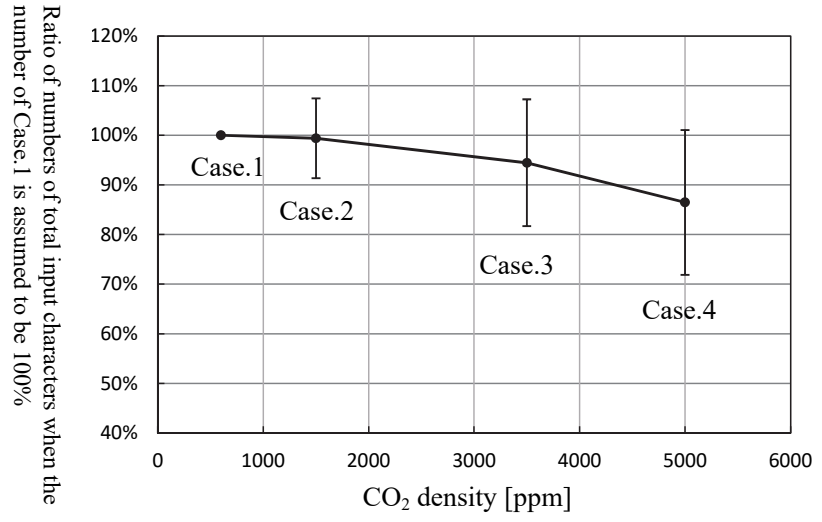

Fig. 10. Relation between the number of total input characters and the $\mathrm{CO}_{2}$ density.

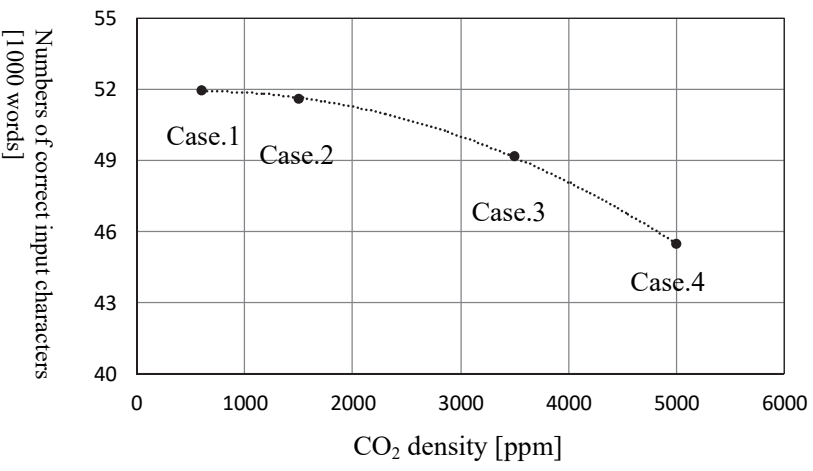

Fig. 11. Relation between the number of correct input characters and the $\mathrm{CO}_{2}$ density.

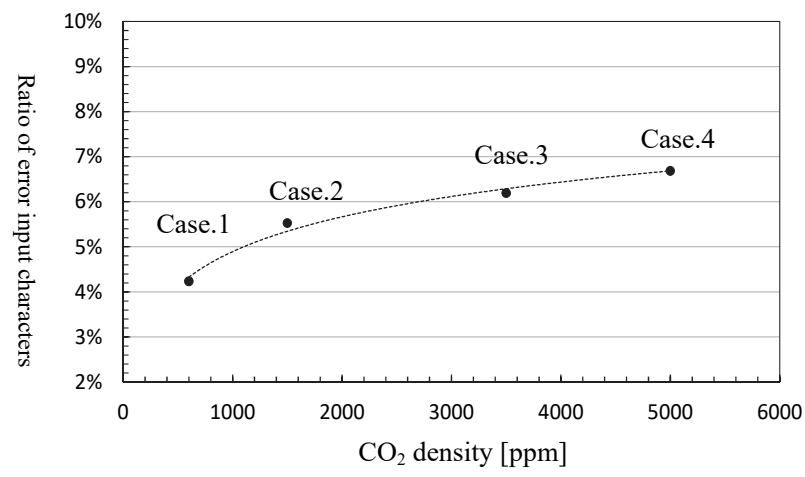

Fig. 12. Relation between the ratio of error input characters and the $\mathrm{CO}_{2}$ density.

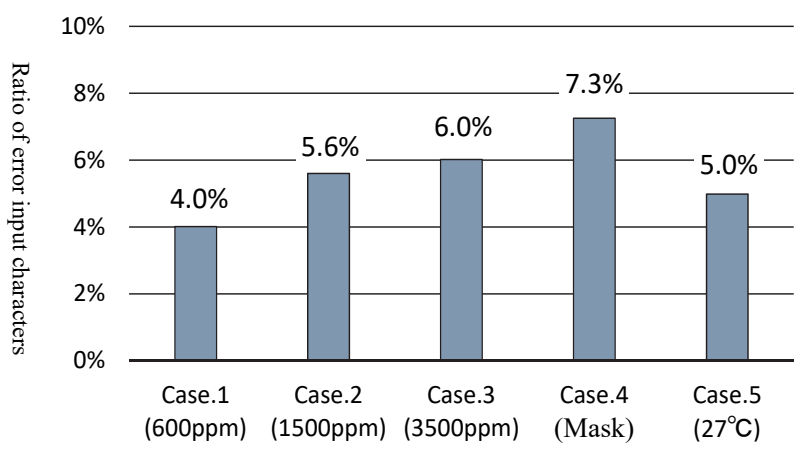

Fig. 13. Relation between the ratio of error input characters and the $\mathrm{CO}_{2}$ density. 


\subsection{Physiological condition}

To verify the physiological condition, tissue oxygenation index (TOI) of the blood in the brain was monitored. Change in concentration of oxygenated haemoglobin ( $\Delta$ $\mathrm{O}_{2} \mathrm{H}_{\mathrm{b}}$ ), deoxygenated haemoglobin $\left(\Delta \mathrm{HH}_{\mathrm{b}}\right)$ and total haemoglobin $\left(\Delta \mathrm{cH}_{\mathrm{b}}\right)$ of the subject's blood flow were also measured, however the result of TOI was shown as a representative. TOI shows the oxygen saturation of the hemoglobin of the blood. The relation between the number of total input characters, the TOI value and the $\mathrm{CO}_{2}$ density is shown in Figure 14. TOI also rose as the typing work. Therefore, Figure 14 shows the averaged TOI value during typing work. As the $\mathrm{CO}_{2}$ concentration rose, similar tendency between the number of characters and TOI was seen.

This time, we did not obtain clear difference of the blood pressure, the pulse and the salivary amylase of the subject.

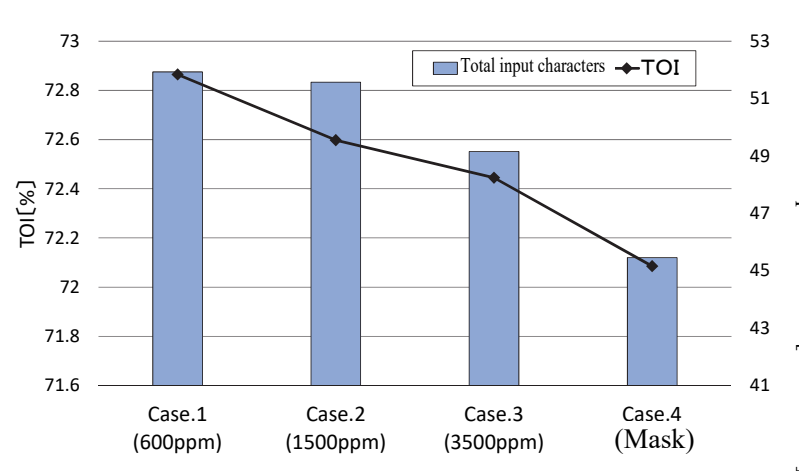

Fig. 14. Relation between the number of total input characters, the TOI value and the $\mathrm{CO}_{2}$ density.

\section{Non-steady $\mathrm{CO}_{2}$ concentration}

\subsection{Subject declaration}

The subject declaration change rates from " $\mathrm{B}$ " to " $\mathrm{C}$ " of Case. 6 and Case. 7 of 6 items (air quality, relaxation level, drowsiness degree, worthlessness feeling, concentrated level and productivity) is shown in Figure 15. The increasing tendency was seen in the drowsiness degree and the worthlessness feeling. And decreasing tendency was seen in the concentrated level and the productivity.

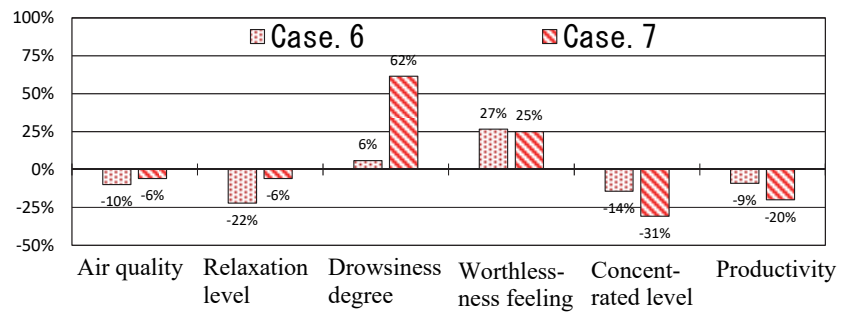

Fig. 15. Subject declaration change rates.

\subsection{Physiological condition}

Tissue oxygenation index (TOI) and the change in concentration of the oxy- hemoglobin $\left(\Delta \mathrm{O}_{2} \mathrm{H}_{\mathrm{b}}\right)$ of the blood also rose as the typing work. Therefore, to analyse the change of the TOI and $\Delta \mathrm{O}_{2} \mathrm{H}_{\mathrm{b}}$, and to examine the physiological mechanism, the added experiments without typing work were conducted.

Figure 16 shows the TOI and $\Delta \mathrm{O}_{2} \mathrm{H}_{\mathrm{b}}$ of Case.6, and Figure 17 shows them of Case. 7.

In Case. $6, \mathrm{CO}_{2}$ concentration is changed from $600 \mathrm{ppm}$ to $1500 \mathrm{ppm}$ gradually after 0 -minute point (Figure 5). At the beginning of the change of the $\mathrm{CO}_{2}$ concentration, it seems to be little difference in the TOI and $\Delta \mathrm{O}_{2} \mathrm{H}_{\mathrm{b}}$. However, after the $\mathrm{CO}_{2}$ concentration reached to 1500 ppm (at 15 minutes' point), both TOI and $\Delta \mathrm{O}_{2} \mathrm{H}_{\mathrm{b}}$ increased rapidly. Even if the $\mathrm{CO}_{2}$ concentration is not so high, physiological condition of the human would be affected by the change of $\mathrm{CO}_{2}$ concentration.

In Case.7, $\mathrm{CO}_{2}$ concentration is changed from $600 \mathrm{ppm}$ to $3500 \mathrm{ppm}$ rapidly after 0 -minute point (Figure 5). As increasing the $\mathrm{CO}_{2}$ concentration, both TOI and $\Delta \mathrm{O}_{2} \mathrm{H}_{\mathrm{b}}$ increased, different from Case.6. However, after a while, they fell. It is thought that it is because of the physiological response of the human body and we will analyse the physiological mechanism further.

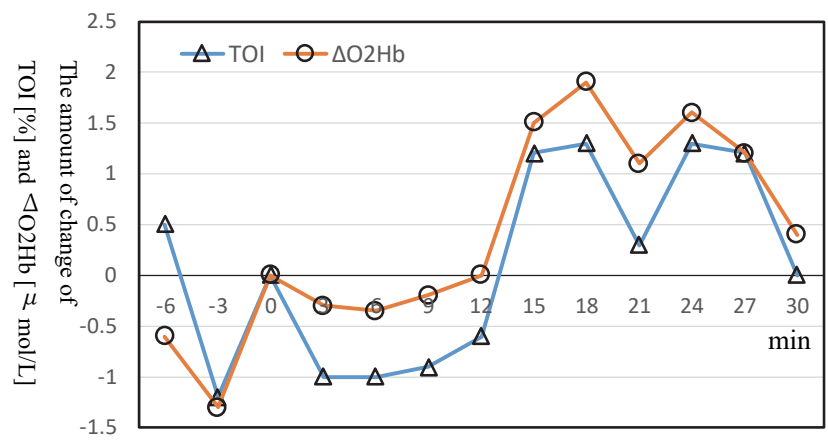

Fig. 16. TOI and the oxy- hemoglobin $\left(\Delta \mathrm{O}_{2} \mathrm{H}_{\mathrm{b}}\right)$ of the blood (Case.6).

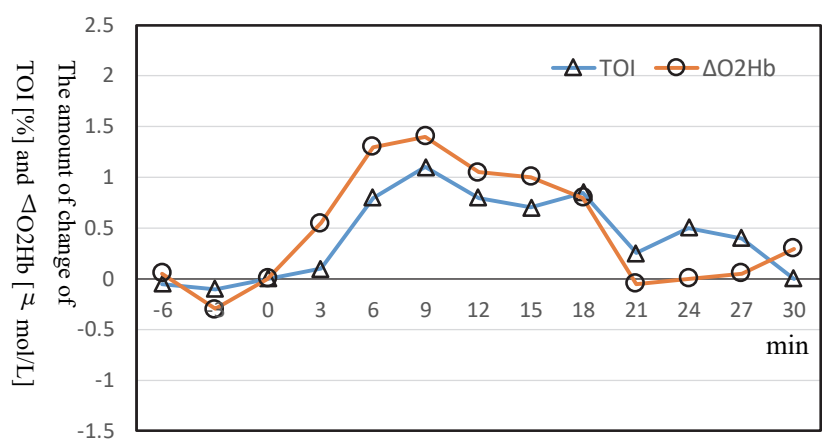

Fig. 17. TOI and the oxy- hemoglobin $\left(\Delta \mathrm{O}_{2} \mathrm{H}_{\mathrm{b}}\right)$ of the blood (Case.7). 


\section{Conclusion and discussion}

We conducted experiments to measure the amount of workability and the physiological and psychological response of the subjects. We used a laboratory room in which not only the $\mathrm{CO}_{2}$ concentration, but also temperature and humidity can be controlled. In the experiment, the concentration of $\mathrm{CO}_{2}$ was set at the constant level at each case to verify the influence of the $\mathrm{CO}_{2}$ concentration. And then, the concentration of $\mathrm{CO}_{2}$ was changed to examine the physiological and psychological response to clarify the mechanism.

The following results were obtained.

The tendency that the drowsiness feeling and the worthlessness feeling grew by high $\mathrm{CO}_{2}$ concentration, was seen from the result of the subjective assessment.

In the result of the typing work, it was suggested that it became a decreasing tendency as the $\mathrm{CO}_{2}$ concentration rose, and the $\mathrm{CO}_{2}$ concentration had the influence on productivity and working efficiency of human.

It has been understood that there is a possibility that the productivity is related to the tissue oxygenation index (TOI) and the change in concentration of the oxyhemoglobin $\left(\Delta \mathrm{O}_{2} \mathrm{H}_{\mathrm{b}}\right)$ of the blood.

It has also been suggested that the change of the $\mathrm{CO}_{2}$ concentration affects the change of the TOI and $\Delta \mathrm{O}_{2} \mathrm{H}_{\mathrm{b}}$ of the blood. Even if the $\mathrm{CO}_{2}$ concentration is not so high, physiological condition of the human would be affected by the change of $\mathrm{CO}_{2}$ concentration.

The authors would like to thank H. Yamada and H. Koji, SHARP Corporation for their support and fruitful discussions with us. We also thank T. Abe for helping the experiments.

\section{References}

1. J. Sundell. "Health and Comfort in Buildings", Sustainable Built Environment Vol.1. EOLSS (2009)

2. U. Satish, M. J. Mendell, K. Shekhar, T. Hotchi, D. Sullivan, S. Streufert, and W. J. Fisk, "Is $\mathrm{CO}_{2}$ an Indoor Pollutant? Direct Effects of Low-toModerate $\mathrm{CO}_{2}$ Concentrations on Human DecisionMaking Performance", Environ Health Perspect (2012)

3. J. G. Allen et.al., "Associations of Cognitive Function Scores with Carbon Dioxide, Ventilation, and Volatile Organic Compound Exposures in Office Workers: A Controlled Exposure Study of Green and Conventional Office Environments", Environmental Health Perspectives, 124-7 (2016)

4. R. Mimura, T. Chikamoto, K. Fukase, Y. Miyazaki, "Relation of Indoor Environment and Learning Effect of Classroom (Part 6) Investigation of Learning Environment and Learning Effect in New Campus in Summer, Autumn and Winter", Proceeding of Annual Meeting, SHASEJ (2016) (in Japanese) 